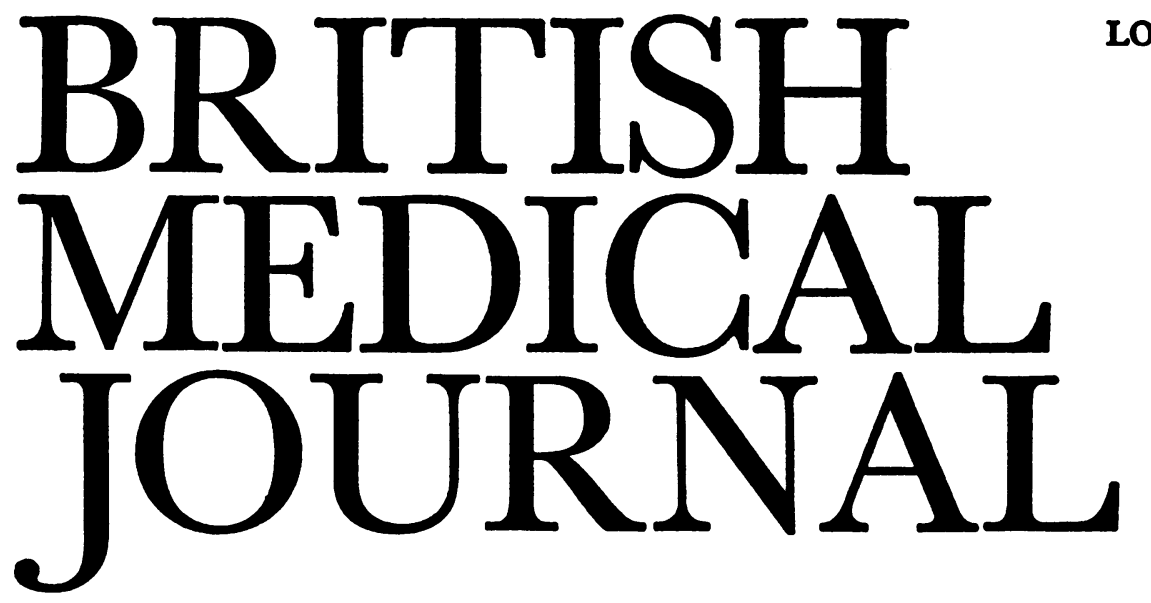

LONDON SATURDAY 11 SEPTEMBER 1971

\title{
Stilboestrol and Cancer
}

The first confirmed reports of the transplacental transmission of cancer in man by means of a hormone, stilboestrol, have recently been published. The evidence provided by this extremely important research, and its significance, need immediate and careful assessment.

Last year A. L. Herbst and R. E. Scully ${ }^{1}$ reported seven cases of adenocarcinoma of the vagina in adolescent girls in the New England area during a period of four years. The patients' ages ranged from 15 to 22 years. They had symptoms of irregular vaginal bleeding for up to one year. Five were treated by radical surgery and one by wide excision. All were alive one to four years after operation. The seventh, in whom the disease was too advanced at surgical exploration, died within six months. The authors were puzzled about the causation of this apparent clustering of cases, as carcinoma of the vagina is uncommon and usually occurs at a much older age.

An eighth case was added in a retrospective study of factors that might have been associated with the appearance of these tumours. ${ }^{2}$ Herbst and colleagues noticed that maternal bleeding when the girl's mother was pregnant with the patient and in previous pregnancies was more common than in a control group. But of greater significance than that was the finding that seven of the eight mothers had been treated with diethylstilboestrol during the first trimester of the material pregnancy, while none of the control group was so treated. A separate study by P. Greenwald and colleagues ${ }^{3}$ has now confirmed this association, adding five more cases in which the actual dosage of synthetic oestrogen used has been obtained.

All 13 patients were born between 1946 and 1953, a period when stilboestrol was being given for repeated or threatened abortion. ${ }^{4}$ All the mothers who took stilboestrol began treatment in the first two months of pregnancy. They received either a constant dose administered throughout pregnancy or a continually increasing dose given almost to term. ${ }^{2}$ The actual dosage varied ${ }^{2} 3$ but followed roughly that suggested by $A$. W. Smith, ${ }^{4}$ beginning at $5 \mathrm{mg}$ by mouth during the sixth or seventh week of pregnancy and increasing by $5 \mathrm{mg}$ at two-weekly intervals to the 15th week, when $25 \mathrm{mg}$ daily was being given. The dose was then increased by $5 \mathrm{mg}$ at weekly intervals until the 35th week, at which time as much as $125 \mathrm{mg}$ of stilboestrol was being taken by mouth daily.

The original series of seven cases exceeded the number of cases in the entire world literature for a tumour of this type in adolescent girls born before $1945 .^{5}$ Indeed, adenocarcinoma of the vagina was thought to have some relationship to vaginal adenosis or to originate from Müllerian-duct or mesonephric remnants. ${ }^{6}$ Moreover, if these neoplasms were the result simply of high-risk pregnancies, this should have become apparent before 1945. It was therefore suspected that exposure to stilboestrol and vaginal carcinoma in the offspring might have a cause-and-effect relationship. 5 The suggestion is reinforced by the fact that stilboestrol was used only infrequently in general obstetric practice. Even at the Boston Hospital for Women, where a special high-risk pregnancy clinic was being conducted, only about one in 21 patients delivered in the wards had received stilboestrol during the five-year period 1946 to 1951.2 Thus when the expectancy of a chance association is less than $5 \%$, the occurrence of maternal stilboestrol therapy in 12 out of 13 cases of vaginal adenocarcinoma in young women cannot be considered coincidental. 5

However, four of the eight families reported ${ }^{2}$ have five female siblings aged 18 to 22 who are products of pregnancies during which their mothers took diethylstilboestrol but who so far have not developed vaginal adenocarcinoma. It would be helpful to know how the children of the other 675 pregnancies in which the mother was known to have had stilboestrol have fared. How many have been traced and what was the incidence of vaginal adenosis?

Stilboestrol is a synthetic nonsteroid oestrogen known to be carcinogenic. ${ }^{7}$ The possible hazards of oestrogen administration have been discussed previously8 with the report of one case of breast cancer after two years of twice-weekly injection of oestradiol monobenzoate for headache, and another of endometrial carcinoma after 10 to $15 \mathrm{mg}$ of stilboestrol daily for 15 years for Turner's syndrome. Thus it is interesting to note that, in mothers exposed to stilboestrol, neoplasms of the breast or genital tract do not seem to develop after the same latent period as the tumour appeared in their daughters. One suggested hypothesis for these tumours is that stilboestrol may initiate the process and the hormonal stimulation of puberty trigger it off. 5 Though the oral contraceptives deserve the thorough study they are receiving, it must be stressed that none of them contains stilboestrol and all the synthetic oestrogens in them are steroids.

The teratogenic and phocomelic effects of drugs in preg- 
nancy have already begun to be appreciated. These studies add another dimension, carcinogenesis. The administration of stilboestrol to the mother in early pregnancy must now be considered as a probable cause of adenocarcinoma developing in their daughters. The onus on investigators is to refute this contention rather than confirm it, and the story should encourage even greater caution before administering any drug to a pregnant woman.

J. Folkman ${ }^{5}$ has raised another issue-namely, the possible effects of stilboestrol residue in meat. Apparently since $195475 \%$ of cattle in America have been fed on stilboestrol to increase their weight. Sweden and other countries have already banned the feeding of this hormone to cattle. ${ }^{8}$ In Britain it has been used on a small scale for some time to fatten veal and some poultry and had been passed as safe under the Voluntary Veterinary Products Safety Protection Scheme. This body was last week superseded by a Veterinary Products Committee set up under the Medicines Commission, and it is to be hoped the new body will examine the facts afresh. Stilboestrol is used for fattening animals in the veal and poultry trade, being injected in a slow-release preparation under the ear of calves and into the back of the head of chickens. These sites have been chosen because they would not enter into human food. But the extent to which stilboestrol may enter it, and the possible consequences, ought to be looked at again.

1 Herbst, A. L., and Scully, R. E., Cancer, 1970, 25, 745.
Herbst, A. L., Ulfeloer, H., and Poskanzer, D. C., New England fournal of Medicine, 1971, 284, 878 .

3 Greenwald, P., Barlow, J. J., Nasca, P. C., and Burnett, W. S., New England Fournal of Medicine, 1971, 285, 390.

Smith, A. W., American fournal of Obstetrics and Gynecology, 1948, 56, 821. s Folkman, J., New England fournal of Medicine, 1971, 285, 404.

Willis, R. A., Pathology of Tumours, 4th edn., p. 560. London, Butterworth, 1967.

'Meissner, W. A., Sommers, S. C., and Sherman, G., Cancer, 1957, 10, 500.

8 Epstein, S., cited by Greenwald et al. ${ }^{3}$

\section{Pathogenesis of Diabetes Mellitus}

Two recent symposia have considered the pathogenesis of diabetes. ${ }^{1} 2$ Curiously, in neither was there any serious discussion of exactly what diabetes is, which in the light of modern knowledge is rather like Hamlet without the Prince of Denmark.

One of the old hypotheses, that diabetes is due to persistent antagonism to insulin, now seems to be untenable. The subject was reviewed by D. M. Kipnis, ${ }^{3}$ who pointed out that the several studies of insulin secretion in patients with an increased statistical risk of developing diabetes (potential diabetics in Britain; prediabetics in the U.S.A.) all showed that the secretion of insulin in them was normal or slightly depressed. Only in obese people is the biological effectiveness of insulin reduced. 45 That an impaired mechanism for the release of insulin is the basic defect in diabetes is now widely canvassed, particularly by $\mathbf{E}$. Cerasi and $R$. Luft. ${ }^{6}$ These investigations have used as their tool a glucose infusion test, measuring levels of blood glucose and plasma insulin. They have laid special emphasis on the initial insulin response and have found it to be impaired in potential diabetics-in this case the healthy members of monozygotic twin pairs of which the other member has diabetes. This abnormality of insulin release was ac- companied by a glucose tolerance response within the normal range. In other people with impaired glucose tolerance or with overt diabetes the initial peak of the insulin response was reduced or missing. This type of abnormality was also seen in $15-20 \%$ of unselected healthy adults and in a similar proportion of children. Cerasi and Luft suggest that people showing this type of insulin response have inherited a predisposition to diabetes, while the actual appearance of the disease is being determined by other factors. Though the findings are similar in other studies of potential diabetics investigated by different methods, the evidence remains circumstantial, and follow-up studies are required on patients with and without the abnormal insulin response to test the hypothesis. It is of course possible to stand the argument on its head by suggesting that the abnormal insulin response in the twin of a diabetic may actually be protecting that person against diabetes, or is linked with some protective mechanism.

A hypothesis at present arousing some controversy is one put forward by $M$. D. Siperstein and his colleagues. ${ }^{7}$ They have measured the thickness of the capillary basement membrane in muscle biopsies taken from diabetics, from normal persons, and from a group of potential diabetics (offspring of two diabetic parents). Siperstein found that the mean thickness of the muscle capillary basement membrane in the diabetics and potential diabetics was greater than in the controls. Thus, $8 \%$ of the normals, $99 \%$ of the diabetics, and $53 \%$ of the potential diabetics exceeded an arbitrary upper limit of normal. He failed to find any thickening of the membrane in patients with secondary diabetes and concluded that hyperglycaemia is not the cause of that thickening of the basement membrane. Rather, he considers, the microangiopathy probably precedes the hyperglycaemia of diabetes and may even cause it. This view receives some slight support from a recent paper by $H$. P. Katz and colleagues. ${ }^{8}$ They observed in young children with diabetes of relatively short duration an increase in the pulse wave velocity, which is influenced by a number of factors, including arterial wall elasticity. ${ }^{9}$ If true, this hypothesis has important implications; hence its controversial nature. Conventional therapy is directed at hyperglycaemia and if this is unrelated to angiopathy the whole basis of treatment will require rethinking. J. R. Williamson ${ }^{10}$ has strongly challenged Siperstein's thesis, however. While using similar techniques, he has been unable to produce Siperstein's results, and it is not clear whether the discrepancies are due to methodological or to sampling differences. It is to be hoped that more data will clarify the issue.

The inescapable conclusion from these discussions is that no single cause can be postulated for all cases of diabetes. This point is emphasized in a contribution by $\mathrm{J}$. $\mathbf{H}$. Edwards ${ }^{11}$ on the genetic aspects of diabetes. He points out that despite extensive study the inheritance of diabetes (like that of other common disorders) remains controversial. Whatever the nature of the mode of inheritance, it seems that environmental factors determine most cases of diabetes, and, as $R$. Levine states," "we should study more the evocative factors which produce overt diabetes, because there is some hope of preventing them."

\footnotetext{
1 Pathogenesis of Diabetes Mellitus, Nobel Symposium 13, ed. E. Cerasi and

R. Luft. Stockholm, Almquist and Wiksell, 1970. Luft and P. J. Randle. Milano, Casa Editrice "Il Ponte," 1971.

- Kipnis, D. M., in Pathogenesis of Diabetes Mellitus, ed. E. Cerasi and R. Luft, p. 45.

- Perley, M., and Kipnis, D. M., Fournal of Clinical Investigation, 1967, 46, 